\title{
Is There an Arms Race Between Pakistan and India? An Application of GMM
}

\author{
Muhammad Ramzan Sheikh* and Muhammad Aslam ${ }^{* *}$
}

\begin{abstract}
This study employs the Richardson model to investigate the presence of an arms race between Pakistan and India during the period 1972-2010. Using the generalized method of moments approach, we find that the grievance term for the Pakistan model is positive while that for India is negative. Both countries' defense spending in the previous period is negatively related to the change in their own defense spending due to the economic or administrative incidence of an arms race. Moreover, the defense or reaction coefficients in the specified model determine the presence of an arms race between the two countries. The signs of these coefficients are positive in accord with the classical Richardson model, suggesting that an arms race does indeed exist between Pakistan and India.
\end{abstract}

Keywords: Arms race, defense spending, generalized method of moments, grievance term, reaction coefficients, Pakistan, India.

JEL classification: C45, H56.

\section{Introduction}

Countries allocate their defense budgets keeping in view several considerations. First, the resources spent on defense could be utilized for other purposes, such as education, health, infrastructure, or social welfare. Second, excess defense spending can hinder economic growth by diverting resources or investment away from potentially more productive uses. Third, there are consequences for regional security: high defense spending and arms acquisition in one country may provoke a similar response from its neighbors and rivals. Even neighbors with no particular fear of attack may be pressurized by their defense establishment to match new technology for reasons of global prestige. Such pressures can lead to regional arms races.

\footnotetext{
* Lecturer, School of Economics, Bahauddin Zakariya University, Multan, Pakistan.

** Assistant Professor, Department of Statistics, Bahauddin Zakariya University, Multan, Pakistan.
} 
Such concerns have raised the issue of defense spending and arms races among academics and policymakers. The global arms race is the focus of considerable campaigning, tactical and legislative attention, and academic study (see, for example, Anderton, 1989; Andreou \& Zombanakis, 2010; Dalton \& Tandler, 2012; Dunne, Nikolaidou, \& Smith, 2005; Kollias \& Paleologou, 2002; Mohammed, 1992; Öcal, 2003; Tahir, 1995; Ward, 1984). While it is an important function of the state to provide and maintain peace in the country by enhancing its defense capabilities in order to safeguard national interests, the question is what budget the government should allocate to arms acquisition.

The international relations literature lays out the phenomenon of the arms race in the context of security dilemmas. An arms race is considered the competition between two or more entities to accumulate weapons, armed forces, advanced military technology, and military might. It is the competitive, resource-constrained, dynamic process of interaction between two states or coalitions of states in their acquisition of weapons (Brito \& Intriligator, 1995).

The arms-race issue has great importance for developing countries such as Pakistan and India. Both allocate an ample share of their budgets to defense, given their internal and external security threats. Over the years, the Indo-Pakistan arms race has become an important area of research (see Öcal, 2003; Phadke, 1988; Yildirim \& Öcal, 2006). Both countries have nuclear capabilities with vital geopolitical and strategic positions, which, arguably, is a form of deterrence to both rivals. This makes it very important to investigate the arms race between two countries that also face very large budget deficits and considerable poverty.

While Sheikh and Chaudhry (2013) investigate the overall determinants of defense expenditure in India and Pakistan (including its economic, political, strategic, military, moral, and psychological aspects), this paper focuses on the military angle under the binary Richardson model. Section 2 describes the classical Richardson model of arms races. Section 3 presents an empirical review of arms-race studies on Pakistan and India. Section 4 presents our methodology and specification of the Richardson arms-race approach. Section 5 discusses the model's results and Section 6 concludes the paper. 


\section{The Richardson Arms Race Approach}

Richardson developed a mathematical model of the arms race in 1960, which showed the defense expenditure patterns of rival nations in an action-reaction framework. It was a seminal study investigating arms races between military rivals. Richardson used two differential equations to explain the arms race. In the classical arms race or Richardson model, each country's weapons acquisition or defense spending is a function of both countries' weapons acquisition or defense spending. The model assumes that each country is a single integrated actor and there is a single homogeneous weapon. A typical Richardson model, as shown by Dunne, Nikolaidou, and Smith (1999), is given by two differential equations:

$$
\begin{aligned}
& \frac{d D_{1}}{d t}=\alpha_{10}+\alpha_{11} D_{1}+\alpha_{12} D_{2} \\
& \frac{d D_{2}}{d t}=\alpha_{20}+\alpha_{21} D_{1}+\alpha_{22} D_{2}
\end{aligned}
$$

where $D_{j}$ is the defense expenditure of country $j(j=1,2), \frac{d D_{1}}{d t}$ is the rate of change in country 1's defense expenditure, $\frac{d D_{2}}{d t}$ is the rate of change in country 2's defense expenditure, $\alpha_{12}$ and $\alpha_{21}$ are the reaction or defense coefficients, $\alpha_{11}$ and $\alpha_{22}$ are the fatigue coefficients, and $\alpha_{10}$ and $\alpha_{20}$ are the grievance terms (or constants); $\alpha_{12}$ and $\alpha_{21}>0$ and $\alpha_{11}$ and $\alpha_{22}<0$.

Equations (1) and (2) reveal that the change in defense spending or weaponry stock of one country is a linear function of its own weaponry stock or defense expenditure, its rival country's weaponry stock or defense expenditure, and a constant or grievance term.

The reaction coefficients $\alpha_{12}$ and $\alpha_{21}$ are assumed to be positive and show that, when the level of defense spending or weaponry stock of one country increases, so does that of its rival country. The fatigue coefficients $\alpha_{11}$ and $\alpha_{22}$ indicate that the rate of change in a country's level of defense spending or weaponry stock is negatively related to its own defense expenditure or arms acquisition, and reflects the economic or administrative incidence of an arms race. Finally, in the Richardson model, $\alpha_{10}$ and $\alpha_{20}$ are grievance terms or constants that will be positive if the two countries have hostile relations and negative if they have friendly relations with each other.

Although the classical Richardson model is considered the most influential formal model of arms races in the literature, its results can prove 
disappointing when applied to data (see Sandler \& Hartley, 1995). This is primarily because the model is theoretical and subject to problems when applied empirically. When any theory is measured empirically to confirm its validity, one must take into account issues such as functional form, the measurement of variables, and lag length, etc., which the theory itself does not. Other problems may relate to data quality and reliability and the results derived may be ambiguous. Finally, various techniques of estimation can present their own problems.

The review of the literature below suggests that different studies on arms-race models have used various estimation techniques, including game theory, dynamic models, forward-looking models, distributed lags or vector autoregression (VAR), error correction, and simultaneous equation systems (see Deger \& Sen, 1990; Dunne \& Smith, 2007; Georgiou, 1990; McGinnis, 1991; Öcal, 2003). New developments in econometrics allow one to apply these techniques to arms race models and investigate why traditional arms race approaches have yielded disappointing results. Accordingly, we apply the generalized method of moments (GMM), which has not yet been used to re-examine the Richardson model.

\section{Arms Race Studies on Pakistan and India: An Empirical Review}

The longstanding military rivalry between Pakistan and India makes them key areas of research in the arms race literature, although no study has drawn a precise conclusion of the arms race between the two neighbors. Hollist (1977) applies the Richardson model and its variants to the arms race between Pakistan and India, using data for the period 1949 to 1973. The reaction coefficients are found to be negative rather than positive (as the Richardson model and its variants would suggest). Hollist thus considers that internal factors may account better for the two countries' defense expenditures.

Deger and Sen (1990) investigate the arms race process in Pakistan and India, using the augmented Richardson model for the period 1960-85. The augmented variables include GDP, arms production, arms imports, and the ratio of central government expenditure to GDP to capture economic factors of defense spending. The study argues that the size asymmetry between the two countries implies that they face dissimilar threats and have different defense perceptions.

Additionally, the study shows that India's one-year lagged defense spending and arms imports are significant factors in determining 
Pakistan's defense spending. The ratio of central government expenditure to GDP suggests that the government has a positive impact on defense budget allocations, while GDP has a minor effect. In India's case, Pakistan's one-year lagged defense spending shows no significant impact on Indian military expenditure. The two variables, arms production and arms imports, are not significant, but GDP is a prime mover of defense spending in India. Overall, the study is inconclusive, implying that, while Pakistan is responsive to Indian defense spending, India is not responsive to Pakistan's defense expenditure.

Oren (1994) evaluates the arms race between Pakistan and India for the period 1947 to 1990. The study reveals that either country's defense spending depends not only on its rival's defense spending, but also on the latter's bellicosity. The latter becomes a stronger factor when the first country has smaller defense expenditures or military power. The findings indicate that both countries' defense spending increases when their rival displays rising aggression. However, both react negatively in response to their rival's defense spending.

Dunne et al. (1999) use the Richardson model to examine the arms race between Pakistan and India for the period 1962-96 under a VAR framework. Using Johansen cointegration, the study suggests there is a long-run relationship between both countries' real defense expenditure (RDE). The reaction coefficients are positive for both countries and there is bidirectional causality between their levels of defense spending.

Öcal (2003) assesses the Indo-Pakistan arms race for the period 1949-99, including the asymmetric effects of both countries' defense spending, based on a smooth-transition nonlinear model. The study finds possible nonlinear dynamics between the two countries' defense expenditures. Yildirim and Öcal (2006) examine the causality between Pakistan and India's defense spending during 1949-2003. Based on seemingly unrelated regressions in a multivariate VAR model, the study applies the Granger causality test and finds bidirectional causality between both countries' defense spending.

Dunne and Smith (2007) reinvestigate the arms race between Pakistan and India, using revised RDE data provided by SIPRI. They reestimate the Richardson model in a VAR framework for the same period as Dunne et al. (1999), but with slightly different results. Subsequently, they extend the time period from 1962 to 2003 . The findings give some indication of a long-run relationship between the countries' RDEs. 
While, for various reasons, none of these studies is strictly conclusive, they do show that a country's defense spending is not determined solely by that of its rival. Other factors, such as conflict history and the dynamics of their defense spending, must also be considered.

\section{Methodology and Specification of the Richardson Approach}

Regression analysis assumes that independent variables are not correlated with the error term and a violation of this assumption would mean that ordinary least squares (OLS) estimators and weighted least squares estimators would be biased and inconsistent. When some of the independent variables are correlated with the disturbance term, they become endogenous variables; those that are uncorrelated with the error term are exogenous variables.

Instrumental variables (IVs) are used when there is an endogeneity problem, especially in a simultaneous equation system. Generally, three basic approaches - two-stage least squares (2SLS), limited information maximum likelihood, and GMM - are used when facing problems of endogeneity and simultaneity. In this case, we use the GMM to account for the endogeneity and simultaneity present in the Richardson model.

The general Richardson model (see eq. 1 and 2) can be written in discrete time and with the stochastic error term as:

$$
\begin{aligned}
& \Delta D_{1 t}=\alpha_{10}+\alpha_{11} D_{1 t-1}+\alpha_{12} D_{2 t}+u_{1 t} \\
& \Delta D_{2 t}=\alpha_{20}+\alpha_{21} D_{1 t}+\alpha_{22} D_{2 t-1}+u_{2 t}
\end{aligned}
$$

These two equations are in autoregressive form where $D_{j t}$ is the defense expenditure of country $j$ at time $t$ where $j=(1,2)$ with 1 representing Pakistan and 2 representing India. The error terms are assumed to satisfy the following properties:

$$
\begin{aligned}
& E\left(u_{j t}\right)=0 \\
& E\left(u_{j}^{2}\right)=\sigma_{j}^{2} \\
& E\left(u_{j t}, u_{k t}\right)=\sigma_{j k} \\
& E\left(u_{j t}, u_{k, t-s}\right)=0 \text { where } s \neq 0 \text { and } j \text { and } k=1,2 .
\end{aligned}
$$

The Richardson model in structural form can be written as: 


$$
\begin{aligned}
& \Delta D_{1 t}=\alpha_{10}+\alpha_{11} D_{1 t-1}+\alpha_{12} \Delta D_{2 t}+\alpha_{13} D_{2 t-1}+u_{1 t} \\
& \Delta D_{2 t}=\alpha_{20}+\alpha_{21} D_{2 t-1}+\alpha_{22} \Delta D_{1 t}+\alpha_{23} D_{1 t-1}+u_{2 t}
\end{aligned}
$$

Substituting eq. (6) into eq. (5), we derive the reduced-form models:

$$
\begin{aligned}
& \Delta D_{1 t}=\pi_{10}+\pi_{11} D_{1 t-1}+\pi_{12} D_{2 t-1}+\varepsilon_{1 t} \\
& \Delta D_{2 t}=\pi_{20}+\pi_{21} D_{1 t-1}+\pi_{22} D_{2 t-1}+\varepsilon_{2 t}
\end{aligned}
$$

The variables $\Delta D_{2 t}$ and $\Delta D_{1 t}$ indicate the presence of endogeneity. Endogeneity implies that, when the explanatory variable is a random variable - that is, not fixed as suggested in the OLS method - and the covariance between that variable and the error term is not equal to 0 , the OLS estimators become biased and inconsistent even in the asymptotic case. Almost all solutions to the endogeneity problem involve the use of IVs. A valid IV should be able to track changes in the endogenous variable reasonably well. In this case, the IVs are $D_{1 t-1}, D_{2 t-1}, \Delta D_{2 t-1}$, and $\Delta D_{1 t-1}$. The first technique that captures endogeneity is 2SLS, which entails (i) regressing the vector of the explanatory variables on the IVs, and (ii) replacing the explanatory variables with the estimated value of the firststage explanatory variable, using OLS to obtain estimators of asymptotically unbiased 2SLS parameters.

In both cases (OLS and 2SLS), the estimator is the ratio of the weighted sum of the dependent variables to the weighted sum of explanatory variables. In each case, the weights used in the numerator and denominator are the same, but the 2SLS estimators use $Z$ (the instrument) as a weight whereas the OLS estimators use $X$ (the explanatory variable). The second technique, the method of moments (MM), is based on the moment condition. If the expected value of the instrument and error term is equal to 0, the MM estimator gives the same estimator as does 2SLS.

When the model is exactly identified, under certain assumptions the MM estimators are the same as the OLS estimators. The MM estimators are derived from moment conditions only when the model is exactly identified. However, if the moment conditions are in excess or overidentified, there is no unique solution for the MM. In this case, the most appropriate technique is the GMM in which all the moment conditions are used optimally by minimizing the sum of the square of deviation of moments from 0 . In the general case of excess moments, the GMM is considered the most efficient compared to other techniques (Hansen, 1982; Studenmund, 2010). 
Over-identifying restrictions mean that the number of instruments is greater than the number of parameters. This minimizes the value of the GMM objective function. The J-statistic (Sagan statistic) is used in the GMM to test the hypothesis of validity for over-identifying restrictions. Under the null hypothesis that the model is correctly specified and overidentifying restrictions satisfied, the J-statistic has an asymptotically $\chi^{2}$ distribution with degrees of freedom (d.f.) equal to the number of overidentifying restrictions (Hansen, 1982).

\section{Data, Trends and Empirical Results}

This section describes the dataset used, the trends that emerge in RDE and economic growth, and the model's results.

\subsection{Data}

The data on Pakistan and India's defense expenditure is, respectively, from the Handbook of Statistics on Pakistan Economy for 2010 (published by the State Bank of Pakistan) and the Handbook of Statistics on the Indian Economy for 2011 (published by the Reserve Bank of India). The data on the dollar exchange rate, GDP at constant 2000 US\$, and GDP at current 2000 US\$ is from the World Development Indicators and Global Development Finance databases for the two countries.

We have converted the variables - the defense expenditures of both countries - from local currency to US $\$$ by means of their respective dollar exchange rates and then deflated the variables using the GDP deflator to find inflation-adjusted or real variables (RDE).

\subsection{Trends in Defense Expenditure and Economic Growth}

Pakistan and India are considered less developed countries with numerous economic and security concerns. As Figure 1 shows, their RDE trends upward from 1972 to 2010. Pakistan's RDE (RDEP) increases from US\$ 1,139.378 million in 1972 to US\$2,897.89 million in 2010, while India's RDE (RDEI) increases from US\$ 3,170.47 million in 1972 to US\$ 11,465.27 million in 2010. Thus, RDEP rises more than twofold in this period while RDEI rises more than threefold. Moreover, the two do not increase at the same pace. 
Figure 1: Trends in RDE, Pakistan and India

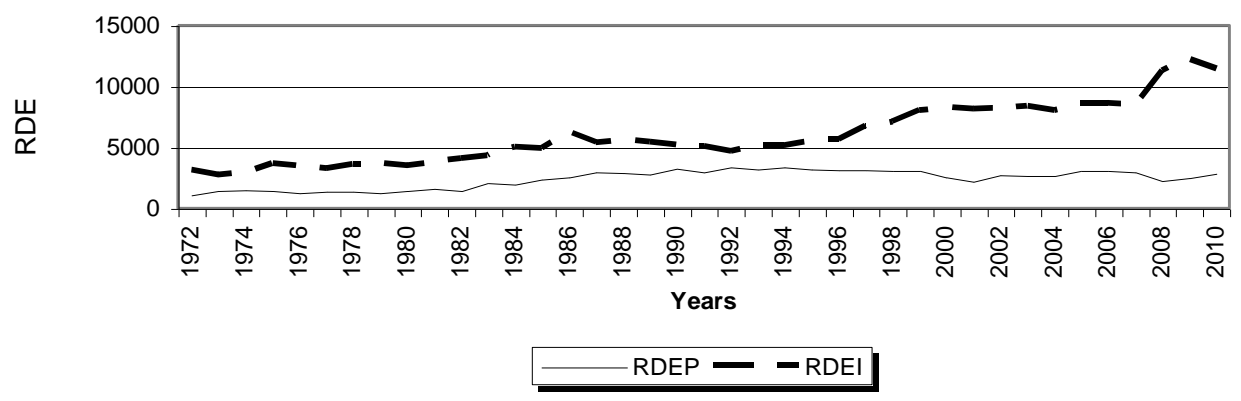

Table 1 summarizes the decade-wise averages and percentage changes in RDEP and RDEI. The overall average RDEP and RDEI is US\$ 2,456.65 million and US\$6,049.96 million, respectively, with the latter more than twice as large as the former. The maximum value of RDEP is US\$ $3,440.833$ million (in 1994) while the minimum value is US\$ $1,139.37$ million (in 1972). Similarly, the maximum value of RDEI is US\$ $12,239.39$ million (in 2009) and the minimum value US\$2,773.41 million (in 1973).

Table 1: Pakistan and India, RDEP and RDEI

\begin{tabular}{lccrc}
\hline Period & RDEP & \% Change & RDEI & \% Change \\
\hline 1972-80 & $1,393.26$ & & $3,364.37$ & \\
$1981-90$ & $2,430.42$ & 74.44 & $5,035.89$ & 49.69 \\
1991-2000 & $3,154.78$ & 29.80 & $6,161.99$ & 22.36 \\
2001-10 & $2,741.78$ & -13.10 & $9,369.04$ & 52.04 \\
Maximum value & $3,440.83$ & & $12,239.39$ & \\
Minimum value & $1,139.37$ & & $2,773.41$ & \\
Overall average & $2,456.65$ & & $6,049.96$ & \\
\hline
\end{tabular}

RDEP increases by 74.44 percent in the first decade of the sample period and by 29.80 percent in the second decade. It then falls by 13.1 percent in the last decade. RDEI increases by 49.69 percent in the first decade and by 22.36 percent in the second decade. In the last decade, RDEI increases dramatically by 52.04 percent in contrast to RDEP.

Next, we apply the augmented Dickey-Fuller test to check the stationarity of the two data series. In both cases, the RDE is integrated of order one, i.e., I(1). This indicates that both variables are nonstationary or have a unit root, but their linear combination becomes stationary. 
Multivariate analyses use variables of the same order of integration (Sims, 1980). Stock and Watson (1996) argue against differencing even if the variables contain a unit root because they can still be used to estimate structural equations. The main argument against differencing is that it "throws away" information on any co-movement in the data (such as the possibility of cointegration). Similarly, the data need not be de-trended (Enders, 2009). We therefore use nonstationary variables in the GMM.

\subsection{GMM Results of the Richardson Model}

The GMM-based results of the Richardson model (eq. 5 and eq. 6) are given in Table 2. In eq. (5) and eq. (6), $D_{j t}(j=1,2)$ is the defense expenditure of either country; eq. (5) is specified for Pakistan and eq. (6) for India. In the first case, the dependent variable is $\Delta D_{1 t}$ and the independent variables are $D_{1 t-1}, \Delta D_{2 t}$, and $D_{2 t-1}$. This shows that a change in Pakistan's defense spending is a function of (i) its own defense spending in the previous period, (ii) a change in India's defense spending, and (iii) India's defense spending in the previous period. The intercept value $\alpha_{10}$ (the grievance term) is 217.24. Since this is positive, it suggests that Pakistan and India are rivals rather than allies. ${ }^{1}$

Pakistan's previous-period defense spending is negatively related to the change in its own defense spending. The value of parameter $\alpha_{11}$ (the fatigue coefficient) is -0.1969 , which is negative (as suggested by theory) and highly significant. This implies that Pakistan's defense spending falls due to an increase in its previous-period defense spending, which is consistent with Richardson's theory: the rate of change in a country's level of defense spending or weaponry stock is negatively related to its own defense expenditure or arms acquisition, and reflects the economic or administrative incidence of an arms race. ${ }^{2}$

\footnotetext{
${ }^{1}$ In the context of positive grievance terms, Sandler and Hartley (1995) observe that, "a nation may augment its armament even though the other nation poses no threat. Grievance may arise from a past defeat (Germany after World War I or Iraq after the Gulf war) or else from territorial or religious disputes." Choucri and North (2001) keep "the constants in the empirically estimated equations to suggest that a given nation may desire a certain amount of arms even if its opponents have no arms." ${ }^{2}$ Sandler and Hartley (1995) comment on the negative fatigue term as follows: "Nation A diminishes its rate of armament expansion in proportion to its existing forces. This expression reflects economic consideration or constraints that limit the nation's ability to redirect resources from civilian uses. Moreover, the fatigue term may also reflect the depreciation of the existing weapons stock as resources must be allocated to maintain current stockpiles."
} 
Table 2: GMM estimates of Richardson model (eq. 5 and 6)

\begin{tabular}{|c|c|c|c|c|c|}
\hline \multicolumn{3}{|c|}{ Pakistan } & \multicolumn{3}{|c|}{ India } \\
\hline \multicolumn{3}{|c|}{ Dependent variable $=\Delta D_{1 t}$} & \multicolumn{3}{|c|}{ Dependent variable $=\Delta D_{2 t}$} \\
\hline$\underline{\text { Regressors }}$ & GMM est. & OLS est. & $\underline{\text { Regressors }}$ & GMM est. & OLS est. \\
\hline Intercept & $\begin{array}{c}217.2413 \\
(0.0728)\end{array}$ & $\begin{array}{c}272.8579 \\
(0.0780)\end{array}$ & Intercept & $\begin{array}{c}-480.1526 \\
(0.0728)\end{array}$ & $\begin{array}{c}206.9299 \\
(0.5805)\end{array}$ \\
\hline$D_{1 t-1}$ & $\begin{array}{c}-0.1969 \\
(0.0061)\end{array}$ & $\begin{array}{c}-0.120464 \\
(0.0822)\end{array}$ & $D_{2 t-1}$ & $\begin{array}{l}-0.0687 \\
(0.1317)\end{array}$ & $\begin{array}{r}0.012339 \\
(0.8103)\end{array}$ \\
\hline$\Delta D_{2 t}$ & $\begin{array}{c}0.4524 \\
(0.0000)\end{array}$ & $\begin{array}{c}-0.167691 \\
(0.0164)\end{array}$ & $\Delta D_{1 t}$ & $\begin{array}{c}2.2102 \\
(0.0000)\end{array}$ & $\begin{array}{c}-0.940983 \\
(0.0164)\end{array}$ \\
\hline$D_{2 t-1}$ & $\begin{array}{c}0.0311 \\
(0.1317) \\
\end{array}$ & $\begin{array}{c}0.017700 \\
(0.4127) \\
\end{array}$ & $D_{1 t-1}$ & $\begin{array}{c}0.4352 \\
(0.0061) \\
\end{array}$ & $\begin{array}{c}-0.007359 \\
(0.9650) \\
\end{array}$ \\
\hline \multicolumn{6}{|c|}{ Diagnostic tests } \\
\hline \multicolumn{3}{|c|}{ Determinant residual covariance } & \multicolumn{3}{|l|}{0.4720} \\
\hline J-statistic & & & 0.0111 & & \\
\hline DW & 2.03 & 2.26 & DW & 2.03 & 2.14 \\
\hline
\end{tabular}

Note: $p$-values in parentheses.

Source: Authors' calculations.

The defense or reaction coefficients $\alpha_{12}$ and $\alpha_{13}$ in the specified model are 0.4524 and 0.0311 , respectively. Their coefficients are positive, indicating that there will be a positive change in Pakistan's defense expenditure in response to India's defense spending. Under the Richardson model, the reaction coefficients $\alpha_{12}$ and $\alpha_{13}$ are assumed to be positive and show that a country's level of defense spending or weaponry stock increases when that of its adversary also increases. Of the two reaction coefficients, the change in India's defense spending is highly significant; the other, India's previous-period defense spending, is not significant.

In the model specified for India, the dependent variable is $\Delta D_{2 t}$ and the independent variables are $D_{2 t-1}, \Delta D_{1 t}$, and $D_{1 t-1}$. It is evident that a change in India's defense spending depends on its own previous-period defense spending and on its rival's change in defense spending and previous-period defense spending. The intercept value, $\alpha_{20}$, is -480.1526 . The fact that the grievance term is negative suggests that Pakistan and India have friendly relations with each other, contrary to the result obtained for Pakistan. This makes it difficult to establish the nature of relations between the two countries on the basis of their grievance terms. 
India's previous-period defense spending is inversely related to the change in its own defense spending. The value of parameter $\alpha_{22}$ (the fatigue coefficient) is -0.0687 . While statistically insignificant, its sign is compatible with the classical arms race theory. The values of the reaction or defense coefficients $\alpha_{21}$ and $\alpha_{23}$ are 2.2102 and 0.4352, respectively. Both variables have the correct signs and are highly significant as proposed by the Richardson model. The positive sign implies that India's defense expenditure will rise in response to an increase in Pakistan's defense spending.

These results are consistent with the arms race studies conducted on Pakistan and India (see Dunne et al., 1999; Yildirim \& Öcal, 2006). However, they contradict studies that find negative reaction coefficients for Pakistan and India (see Hollist, 1977; Oren, 1994; Öcal, 2003). Further, some studies provide no evidence of an arms race between Pakistan and India (see Deger \& Sen, 1990).

The value of the Durbin-Watson (DW) statistic for both equations is 2.03, which indicates there is no evidence of autocorrelation. We use four instruments to estimate the three parameters, so there is one overidentifying restriction. The critical value of the J-statistic $\chi_{1}^{2}$ is 1.534 at a 5 percent level of significance. Therefore, we are unable to reject the null hypothesis and conclude that the model is correctly specified and the overidentifying restrictions valid. The OLS estimates are also reported, although these are not reliable in case of an endogeneity problem.

\subsection{Reduced-Form Empirical Results}

The reduced-form empirical results of the Richardson model (eq. 7 and 8) are given in Table 3. These equations demonstrate that a change in one country's defense expenditure depends on its own previous-period defense expenditure and that of its rival. Since the reduced-form equations have no inherent simultaneity, they do not violate the classical assumption that all explanatory variables are uncorrelated with the error term. Therefore, they can be estimated using OLS.

Eq. (7) is specified for Pakistan and has two independent variables - its own previous-period defense spending and that of its rival, India besides the intercept or grievance term. The sign of the grievance term is positive as found for the GMM estimates. The estimated value of the parameter of Pakistan's own previous-period defense spending $\left(D_{1 t-1}\right)$ is -0.1416 . As the Richardson theory would suggest, this is negative and highly significant. The result shows that Pakistan's previous-period defense spending is negatively related to its own defense expenditure. 
Table 3: Reduced-form estimates of Richardson model (eq. 7 and 8)

\begin{tabular}{|c|c|c|c|}
\hline \multicolumn{2}{|c|}{$\begin{array}{l}\text { Pakistan } \\
\end{array}$} & \multicolumn{2}{|c|}{ India } \\
\hline \multicolumn{2}{|c|}{ Dependent variable $=\Delta D_{1 t}$} & \multicolumn{2}{|c|}{ Dependent variable $=\Delta D_{2 t}$} \\
\hline$\underline{\text { Regressors }}$ & Estimates & $\underline{\text { Regressors }}$ & Estimates \\
\hline Intercept & $\begin{array}{l}282.7885 \\
(0.0441)\end{array}$ & Intercept & $\begin{array}{l}-59.1599 \\
(0.4389)\end{array}$ \\
\hline$D_{1 t-1}$ & $\begin{array}{l}-0.1416 \\
(0.0281)\end{array}$ & $D_{2 t-1}$ & $\begin{array}{l}-0.0051 \\
(0.4627)\end{array}$ \\
\hline$D_{2 t-1}$ & $\begin{array}{l}0.0186 \\
(0.2120)\end{array}$ & $D_{1 t-1}$ & $\begin{array}{l}0.1259 \\
(0.2317)\end{array}$ \\
\hline \multicolumn{4}{|l|}{ Diagnostic tests } \\
\hline DW & 2.17 & DW & 2.06 \\
\hline BPG test & 0.5386 & BPG test & 0.2788 \\
\hline Jarque-Bera (prob.) & 0.9141 & Jarque-Bera (prob.) & 0.0000 \\
\hline
\end{tabular}

Note: $p$-values in parentheses.

Source: Authors' calculations.

The second variable is India's previous-period defense spending $\left(D_{2 t-1}\right)$. The estimated value of the reaction coefficient is 0.0186 , which is positive as suggested by the theory, but not significant in our model. The results correspond to those obtained from the GMM model. The values of the DW and Breusch-Pagan-Godfrey (BPG) statistics suggest that we cannot reject the null hypothesis of no autocorrelation or heteroskedasticity of residuals, respectively. The probability value of the Jarque-Bera test statistic shows that the residuals are normally distributed.

Eq. (8) is specified for India with similar variables. The sign of the grievance term is negative, similar to the GMM model. The estimated value of the parameter of India's previous-period defense spending $\left(D_{2 t-1}\right)$ is -0.0051 , which is negative but not significant. This shows that India's previous-period defense spending is negatively related to its own defense expenditure.

The second variable is Pakistan's previous-period defense spending $\left(D_{1 t-1}\right)$. The estimated value of the reaction coefficient is 0.0126 , which is positive but statistically not significant. The DW and BPG values suggest that we are unable to reject the null hypothesis of no autocorrelation and heteroskedasticity of residuals, respectively. The probability value of the Jarque-Bera test shows that the residuals are not normally distributed. However, since the sample is small, this does not pose a serious problem. 
Overall, the reduced-form estimates of the Richardson model are poor in terms of statistical significance, although their signs are compatible with classical arms race theory. Many such studies do not yield good results (see, for example, Isard \& Anderton, 1988; Deger \& Sen, 1990; Georgiou, 1990; Kollias, 1991; McGinnis, 1991; Sandler \& Hartley, 1995; Georgiou, Kapopoulos, \& Lazaretou, 1996; Kinsella \& Chung, 1998). However, the structural parameters, which researchers are more likely to consider, are better than the reduced-form estimates.

\section{Conclusion}

This study has attempted to gauge the presence of an arms race between Pakistan and India. In order to overcome the simultaneity and endogeneity problems, we have applied a GMM model to the Richardson arms race model for data spanning 1972-2010. The Richardson model predicts that a change in one country's defense spending is a function of its defense spending in the previous period, a change in its rival's defense spending, and its rival's defense spending in the previous period.

We have specified structural parameter equations for both countries. The grievance term in Pakistan's model is positive, indicating that Pakistan and India have hostile relations. The economic or administrative incidence of an arms race is captured by Pakistan's previous-period defense spending or fatigue coefficient, which is highly significant and negatively related to changes in Pakistan's own defense spending - as suggested by Richardson's theory. The reaction coefficients are positive, indicating that there will be a positive change in Pakistan's defense expenditure in response to India's defense spending.

The intercept value in India's model is, however, negative, which implies that the two countries have friendly relations. This contradicts the results for Pakistan and makes it difficult to draw any conclusion on the basis of the grievance terms. Our findings also show that India's previousperiod defense spending is statistically insignificant and inversely related to changes in India's own defense spending. The reaction coefficients are positive and highly significant.

We have also estimated reduced-form equations demonstrating that a change in one country's defense expenditure depends on the previous-period levels of its own and its rival's defense expenditures. While these estimates are found to be poor statistically, their signs are compatible with the classical theory of arms races. Finally, the overall analysis indicates that an arms race does exist between Pakistan and India. 


\section{References}

Anderton, C. H. (1989). Arms race modeling: Problems and prospects. Journal of Conflict Resolution, 33(2), 346-367.

Andreou, A. S., \& Zombanakis, G. A. (2010). Financial vs. human resources in the Greek-Turkish arms race 10 years on. Retrieved from http://mpra.ub.uni-muenchen.de/38505/

Brito, D. L., \& Intriligator, M. D. (1995). Arms races and proliferation. In K. Hartley \& T. Sandler (Eds.), Handbook of defense economics (vol. 1, pp. 109-164). Amsterdam: Elsevier.

Choucri, N., \& North, R. C. (2001). Nations in conflict: Data on national growth and international violence for six European major powers, 1870-1914. Ann Arbor, MI: Inter-University Consortium for Political and Social Research.

Dalton, T., \& Tandler, J. (2012). Understanding the arms "race" in South Asia. Washington, DC: Carnegie Endowment for International Peace.

Deger, S., \& Sen, S. (1990). Military security and the economy: Defense expenditure in India and Pakistan. In K. Hartley \& T. Sandler (Eds.), The economics of defense spending (pp. 189-227). London: Routledge.

Dunne, J. P., Nikolaidou, E., \& Smith, R. P. (1999, June). Arms race models and econometric applications. Paper presented at the Conference on the Arms Trade, Security and Conflict, Middlesex University Business School, UK.

Dunne, J. P., Nikolaidou, E., \& Smith, R. P. (2005). Is there an arms race between Greece and Turkey? Peace Economics, Peace Science and Public Policy, 11(2), 1-37.

Dunne, J. P., \& Smith, R. P. (2007). The econometrics of military arms races. In T. Sandler \& K. Hartley (Eds.), Handbook of defense economics (vol. 2, pp. 913-940). Amsterdam: Elsevier.

Enders, W. (2009). Applied econometric time series (3rd ed.). New York, NY: Wiley. 
Georgiou, G. (1990). Is there an arms race between Greece and Turkey? Some preliminary econometric results. Cyprus Journal of Economics, $3,58-73$.

Georgiou, G., Kapopoulos, P., \& Lazaretou, S. (1996). Modeling GreekTurkish rivalry: An empirical investigation of defense spending dynamics. Journal of Peace Research, 33(2), 229-239.

Hansen, L. P. (1982). Large sample properties of generalized method of moments estimators. Econometrica, 50(4), 1029-1054.

Hollist, W. L. (1977). An analysis of arms processes in the United States and the Soviet Union. International Studies Quarterly, 21(3), 503-528.

Isard, W., \& Anderton, C. H. (1988). A survey of arms race models. In W. Isard (Ed.), Arms races, arms control and conflict analysis (pp. 17-85). Cambridge: Cambridge University Press.

Kinsella, D., \& Chung, S.-M. (1998). The long and the short of an arms race. In M. Wolfson (Ed.), The political economy of war and peace (pp. 223246). Boston, MA: Kluwer.

Kollias, C. G. (1991). Greece and Turkey: The case study of an arms race from the Greek perspective. Spoudai, 41, 64-81.

Kollias, C., \& Paleologou, S.-M. (2002). Is there a Greek-Turkish arms race? Some further empirical results from causality tests. Defense and Peace Economics, 13(4), 321-328.

McGinnis, M. D. (1991). Richardson, rationality and restrictive models of arms races. Journal of Conflict Resolution, 35(3), 443-473.

Mohammed, N. A. (1992). Military expenditure in sub-Saharan Africa: A comparative analysis and case study of the Sudan. Unpublished PhD dissertation, University of Cambridge, UK.

Öcal, N. (2003). Are the military expenditures of India and Pakistan external determinants for each other? An empirical investigation. Defense and Peace Economics, 14(2), 141-149.

Oren, I. (1994). The Indo-Pakistani arms competition: A deductive and statistical analysis. Journal of Conflict Resolution, 38(2), 185-214. 
Phadke, A. (1988). Preventing nuclear arms race between India and Pakistan: A practical proposal. Economic and Political Weekly, 23(34), 1741-1743.

Sandler, T., \& Hartley, K. (1995). The economics of defense. Cambridge: Cambridge University Press.

Sheikh, M. R., \& Chaudhry, I. S. (2013). The determinants of defense expenditures in Pakistan and India: An ARDL bounds testing approach. Pakistan Journal of Social Sciences, 33(1), 199-215.

Sims, C. A. (1980). Macroeconomics and reality. Econometrica, 48(1), 1-48.

Stock, J. H., \& Watson, M. W. (1996). Evidence on structural instability in macroeconomic time series relations. Journal of Business and Economic Statistics, 14(1), 11-29.

Studenmund, A. H. (2010). Using econometrics: A practical guide (6 ${ }^{\text {th }}$ ed.). Upper Saddle River, NJ: Prentice Hall.

Tahir, R. (1995). Defense spending and economic growth: Re-examining the issue of causality for Pakistan and India. Pakistan Development Review, 34(4), 1109-1117.

Ward, M. D. (1984). Differential paths to parity: A study of the contemporary arms race. American Political Science Review, 78(2), 297-317.

Yildirim, J., \& Öcal, N. (2006). Arms race and economic growth: The case of India and Pakistan. Defense and Peace Economics, 17(1), 37-45. 
